\title{
EDUCAÇÃO ESPECIAL NA PERSPECTIVA DA EDUCAÇÃO INCLUSIVA NO MUNICÍPIO DE BOA VISTA, RORAIMA
}

\author{
Maria Edith Romano Siems ${ }^{1}$ (D) \\ Wellington Alves ${ }^{2}$
}

\begin{abstract}
RESUMO: Neste artigo apresentamos de que forma as políticas nacionais de educaçáo especial em sua perspectiva de educação inclusiva vem sendo significadas no município de Boa Vista, no período de 2006 a 2016, e práticas decorrentes dessas políticas. O estudo é desenvolvido por meio de análise documental a partir de normativos legais municipais, relatórios do órgão gestor da educação especial no município e relatos de experiência de professores que atuam nas salas de recursos multifuncionais. Identificamos que o foco da educação especial se centra nesses espaços.
\end{abstract}

Palavras-chave: Educação especial. Educação inclusiva. Políticas educacionais.

\section{Special education in the perspective of inclusive education in the municipality of Boa Vista, Roraima, Brazil}

ABSTRACT: In this article, we present how the national policies to Special Education, in the perspective of Inclusive Education, have been signified in the municipality of Boa Vista in the period from 2006 to 2016 as well as the practices resulting from

\footnotetext{
${ }^{1}$ Universidade Federal de Roraima, Centro de Educaçáo - Boa Vista (RR), Brasil. E-mail: edith.romano@ufrr.br

${ }^{2}$ Universidade Estadual de Roraima - Boa Vista (RR), Brasil.

E-mail: maverickrr@hotmail.com
}

DOI: $10.1590 / C C 0101-32622018195843$ 
these policies. The study is developed through documentary analysis, based on municipal legal norms, reports of the special education management body and reports of teachers who work in Multifunctional Resource Rooms. We have identified that the focus of special education concentrates on Multifunctional Resource Rooms.

Keywords: Special education. Inclusive education. Educational policies.

\section{INTRODUÇÃO}

$1 \begin{aligned} & \text { educação especial no estado de Roraima desenvolveu-se a } \\ & \text { partir dos anos } 1970 \text { com características bastante diferencia- } \\ & \text { das do restante do país. Como antigo território federal, de }\end{aligned}$ gestáo direta do governo central até o fim da década de 1990, foram implantados serviços especializados destinados ao atendimento dos estudantes por meio dos setores responsáveis pela gestáo da educaçáo e integralmente sob responsabilidade governamental.

Esses serviços de educação especial se estruturam na perspectiva de escolarizaçáo de todos os estudantes, com o protagonismo de professores, articulados à rede regular de ensino e, em muitos casos, antecipando-se nos encaminhamentos em perspectiva inclusiva que posteriormente viriam a se disseminar no país. Não há registros da existência de instituiçóes privadas de natureza assistencial ou filantrópica que trouxessem impactos ao processo de escolarização dos estudantes público-alvo da educação especial.

No município de Boa Vista, capital do estado, encontra-se instalado o Centro Municipal Integrado de Educação Especial (CMIEE) que realiza, desde sua criação em 1991, atendimento educacional especializado a estudantes da rede municipal que demandem apoio ao seu desenvolvimento ou aprendizado em caráter complementar à escolarização e não substitutivo desta, além do apoio aos professores e escolas que o demandem.

Neste artigo buscamos, por meio de análise documental na perspectiva da análise de conteúdo de documentos do setor educacional 
municipal, compreender de que forma as políticas públicas impactaram no município de Boa Vista, que açóes decorreram das reorientaçóes nas políticas nacionais de educação especial e de que forma as práticas decorrentes dessas políticas se articulam, ou não, às experiências já existentes entre os profissionais e serviços da rede municipal de ensino.

É possível observar que os discursos locais relativos ao trabalho desenvolvido trazem em si as marcas discursivas das políticas nacionais aqui, entretanto, ressignificadas, como nos aponta Bakhtin (2006), trazendo no formato adotado para sua execução os sentidos peculiares constituídos a partir das marcas anteriores de estruturação local da área da educação especial.

\section{O ATENDIMENTO EDUCACIONAL ESPECIALIZADO NO MUNICÍPIO DE BOA VISTA: PRIMEIRAS APROXIMAÇÕES}

No município de Boa Vista, os serviços de educação especial implantados foram todos inicialmente vinculados à Secretaria de Educação, seguindo as orientaçóes do órgão federal responsável pela área.

Dessa forma, chegamos a 2008 contando, entre outras estruturas, com um Centro Estadual de Educação Especial, um Centro de Apoio Pedagógico para os Deficientes Visuais (CAP), um Centro de Atendimento às Pessoas com Surdez (CAS), um Centro de Estimulação Precoce e um Núcleo de Triagem e Avaliação. Todas essas unidades, além do apoio aos estudantes da rede estadual de ensino, encontram-se aptas também ao atendimento dos estudantes da rede municipal e privada de ensino.

$\mathrm{Na}$ rede municipal, o CMIEE realiza atendimento especializado a alunos com deficiência na forma de apoios clínicos, terapêuticos e psicopedagógicos aos estudantes. Esse, desde seus primórdios, oferecia aos alunos o acesso a fisioterapeutas, fonoaudiólogos, psicólogos, assistentes sociais e terapeutas ocupacionais e passa a contar, a partir de 1995, com a atuação de pedagogos a fim de "aprofundar a articulação deste trabalho com as necessidades educativas das crianças em sua trajetória escolar" (SIEMS, 2016, p. 236).

Da criação do CMIEE aos dias atuais, várias foram as alteraçóes vivenciadas nas políticas nacionais da área, entretanto a prática de ma- 
tricular os estudantes público-alvo da educação especial em turmas de ensino regular e lhes oferecer o acesso aos acompanhamentos de apoio clínico ou pedagógico que fosse possível, em acordo com a disponibilidade de recursos materiais e técnicos do CMIEE, marcam a identidade da educação oferecida nas séries iniciais das escolas de Boa Vista, em especial para os alunos da rede municipal de ensino.

O desafio a que nos propomos nesse estudo é compreender, nesse contexto singular, de que forma foram incorporadas localmente, no período de 2008 a 2016, as políticas nacionais de educação especial em sua perspectiva de estruturaçáo da educação inclusiva adotadas pelo governo federal.

\section{METODOLOGIA}

Apresentamos uma pesquisa na qual analisamos o impacto, na rede municipal de Boa Vista, das políticas nacionais disseminadas pelo Ministério da Educação nos anos 2000.

O estudo foi desenvolvido por meio de análise documental e tomamos, como corpus de conhecimento, materiais produzidos por profissionais atuantes nos serviços de educação especial, bem como documentos que orientam e normatizam a realização das atividades.

Destacamos um portfólio institucional da Coordenação de Educação Especial da Secretaria Municipal de Educação que registra as atividades desenvolvidas entre os anos de 2006 e 2012. Analisamos, também, 63 relatos de experiência no formato de artigos científicos produzidos no ano de 2016 pelos docentes atuantes nas salas de recursos multifuncionais destinados à apresentação na IV Mostra de Educação Especial do município.

Da legislação municipal, analisamos o Plano de Cargos, Carreiras e Remuneração (PCCR) da Prefeitura de Boa Vista (PMBV) e a lei municipal que regulamenta a função de cuidadores.

$\mathrm{Na}$ leitura e análise do material evidencia-se como os discursos disseminados nos normativos das políticas nacionais de educação especial foram incorporados e, nesse sentido, entendemos a possibilidade de reflexão a partir dos estudos de linguagem de Bakhtin (2006), que destaca a possibilidade de reconhecer os discursos do outro nas falas de 
cada um e de como, nessa incorporação de discursos alheios, sempre se observam modificaçóes e apropriaçóes seletivas. São as várias vozes como condição da existência do discurso.

\section{RESULTADOS}

No portfólio da Coordenação de Educação Especial (CEE) denominado de Resultados de um processo (BOA VISTA, 2012a) há o registro do processo histórico de implantação dos serviços de educação especial no período de 2006 a 2012. Sua apresentação enuncia como objetivo o de "apresentar o trabalho desenvolvido por esta Coordenação junto às escolas":

Ao final espera-se que, quem desse portfólio tenha acesso, venha visualizar os resultados alcançados ao longo de um processo que teve início em 2006, e, hoje, passados seis anos de trabalho árduo, deslumbramos um total de 33 (Salas de Recursos Multifuncionais) SRMs e 14 escolas esperando para ser contempladas pelo Ministério da Educação e Cultura - MEC, pois inicialmente eram atendidos 180 alunos, hoje chega a 466 alunos atendidos, além de contar com o apoio prestado pelo Centro Municipal Integrado de Educação Especial - CMIEE. Processo esse que sinaliza um novo conceito de Educação Especial, pois a ideia é prestar o AEE a todos os alunos que dele necessitem, além de garantir o direito legal de todos à educação (BOA VISTA, 2012a).

Nas próximas etapas, o documento apresenta as ações desenvolvidas pela CEE desde sua criação em 2006. Nesse ano, os trabalhos são iniciados pelo esforço de identificar o quantitativo de alunos com necessidades educacionais especiais atendidos. Os objetivos da coordenação dividem-se em apoiar e orientar as escolas para a implementação da educação inclusiva, além de capacitar os profissionais da educação e disponibilizar subsídios teórico-práticos para construção de escola para a diversidade. Há quatro eixos temáticos apontados: "monitoramento, formação continuada, implementação e aprimoramento do Atendimento Educacional Especializado (AEE) e Comunidade” (BOA VISTA, 2012a). 
Ao longo do período 2006-2012 há uma progressão geométrica da expansão das salas de recursos multifuncionais (SRMs). Inicialmente presentes em apenas cinco escolas, chegam ao final de 2012 com 33 salas implantadas, que representa uma cobertura, entáo, superior a $50 \%$ da rede, que conta com aproximadamente 60 escolas, quantitativo atendido em 2016.

É possível identificar que esse processo tem total correlaçẫo com o lançamento pelo Ministério da Educação (MEC) do Programa de Implantação de Salas de Recursos Multifuncionais (BRASIL, 2006), que define esse serviço como alternativa preferencial para o apoio à escolarização das crianças público-alvo da educação especial.

Da análise das açôes realizadas infere-se que, dos quatro eixos temáticos apontados, a ênfase está posta na formação dos professores e dos técnicos, com a oferta sistemática de açôes de formação em diferentes formatos como simpósios, cursos e encontros, entre outros.

Em 2009, observa-se também preocupação com a adequação do perfil dos professores que atuarão em educação especial. Embora não haja referência a um professor de educação especial como categoria específica, observa-se um sentido de busca de docentes que tenham indícios de interesse pela área, indicando-se o fato de que a seleção ocorreu por análise curricular e entrevistas (BOA VISTA, 2012a).

No ano de 2012, uma das açōes enunciadas foi a Multiplicação do Decreto dos Cuidadores. O decreto citado é a Lei municipal no $1.411 / 2012$ (BOA VISTA, 2012b), que insere o cuidador na estrutura de cargos dos servidores efetivos do poder executivo municipal. Prevê-se que esse será um profissional de nível médio, destinado a cuidar de crianças, jovens, adultos e idosos, mas, no anexo que descreve as atribuiçóes desse profissional, o foco está no atendimento a pessoas com deficiência.

Em fevereiro de 2014, com a aprovação do PCCR da PMBV, surgem os cargos de assistente - cuidador de nível médio, de professor de educaçáo infantil bilíngue - língua brasileira de sinais (Libras) e de analistas em educação nas áreas de assistência social, fonoaudiologia, fisioterapia e terapia ocupacional, todos de nível superior e que também apoiam estudantes sem necessidades especiais.

Uma definição de cargo dá indícios do impacto das políticas públicas nacionais no município. Trata-se do professor de sala multifuncio- 
nal, cujas atribuiçóes indicam tratar-se de um cargo cujo perfil demandaria a contratação de um professor especialista em educação especial. Partimos, aqui, do pressuposto de que, ao nos referirmos à educação especial, estamos entendendo-a "enquanto uma área de conhecimento científico e um campo de atuação profissional” (MENDES, 1995, p. 254) que tem, na proposição de educação inclusiva, uma perspectiva de escolarização que, na legislação educacional brasileira atual, não exclui a possibilidade de educação escolar em espaços não inclusivos. Milanesi (2012, p. 26), apoiada em Mendes (2009), traz-nos uma importante reflexão sobre essa questão:

Mendes (2009) considera que a opçáo política da Secretaria de Educação Especial (SEESP) de priorizar a chamada "classe de recurso multifuncional" como uma espécie de "serviço tamanho único", quando ela deveria ser apenas mais um dos vários serviços de sistema do contínuo dos serviços, representa uma simplificação dos serviços de apoio, o que não encontra sustentação na literatura da área de Educação, em termos de efetividade, para atender às necessidades tão diversificadas deste alunado (MILANESI, 2012, p. 26).

E é exatamente essa perspectiva redutora e simplificadora que vemos aqui materializada. $\mathrm{Na}$ transposição de uma organização de serviços proposta na política nacional vemos a transmutação de uma demanda por um profissional com formação e desenvolvimento profissional em um campo específico, a educação especial, em um cargo de professor de sala de recursos multifuncionais. Dessa forma, uma política de governo é alçada a campo de atuação num plano de cargos e carreiras que projeta a organização, a longo prazo, de um sistema.

Passamos aqui a um novo contexto de constituição de um signo que conforme Bakhtin (2006, p. 44) é "o resultado de um consenso entre os indivíduos socialmente organizados no decorrer de um processo de interação". A modificação do sentido da existência de um professor de educação especial a um professor de salas de recursos multifuncionais pode ser pactuada, considerando-se que, nessa mesma ótica "as formas do signo são condicionadas tanto pela organização social de tais indivíduos como pelas condiçóes em que a interação acontece" (BAKHTIN, 2006, p. 44). 
Não encontramos, nos documentos aqui estudados, nenhum questionamento explícito quanto à criaçáo, no ordenamento legal municipal, de cargos como cuidadores e professores de salas de recursos multifuncionais. Esses vêm sendo definidos como postos de trabalho, sem que se vincule sua qualificação ou atuação ao campo da educação especial. Em nosso entendimento, profissionais especializados em uma área de conhecimento estabelecida e solidificada teriam melhores condiçóes de efetivar a educação escolar em perspectiva inclusiva, dos estudantes público-alvo da educação especial.

Consideramos ainda que, mesmo resguardada a possibilidade de alteração de categorias profissionais pelos sistemas municipais, a implantação de salas de recursos multifuncionais é uma política de governo cuja natureza recente demandaria pesquisas quanto à eficácia do modelo adotado e que, evidentemente, necessitaria contar com os saberes do campo da educação especial. Além disso, as necessidades específicas dos estudantes são tão variadas e sujeitas a tantas peculiaridades e variabilidade que, dificilmente, apenas a oferta de SRM será suficiente para atendê-las.

Em revisão de produção de conhecimento realizada por Pasian, Mendes e Cia (2014), identificou-se 14 artigos científicos que tomaram por foco as salas de recursos multifuncionais, dando indicativos da relevância que essa temática vem assumindo nos estudos da área.

Baptista (2011), refletindo sobre possíveis benefícios da adoção do modelo de salas de recursos por seu potencial de atendimento a necessidades específicas da condição dos estudantes, questiona as afirmativas que tratam da política de salas de recursos multifuncionais tratando-a como se estivesse sendo "confundida com a defesa de um modelo único para o país”(BAPTISTA, 2011, p.72).

Entretanto, analisando a realidade dos serviços que se instalaram nas escolas de ensino fundamental do município de Boa Vista e a interlocução restrita com os demais espaços destinados ao atendimento especializado, como o CMIEE, verificamos que a consequência dessa proposição do governo federal foi a adoção de uma atuação específica como modelo único e permanente, embora ainda seja necessária a realização de estudos em maior profundidade quanto à sua efetividade em termos de resultados pedagógicos. 


\section{O QUE NOS CONTAM OS PROFESSORES SOBRE SUAS EXPERIÊNCIAS}

Os relatos de experiência que tomamos aqui como fonte para a análise dos processos de desenvolvimento das atividades na escola não estão oficialmente publicados até o momento, razão pela qual não fazemos a indicação individualizada de autoria nos trechos que destacamos.

Segundo descrito em um encontro de formação continuada promovido pela Coordenação de Educação Especial em março de 2016, cujo tema foi Orientaçóes para a elaboraçáo do relato de experiência, esse processo de orientação para a construção dos relatos de experiência possibilita compreender o padrão de regularidade na formatação dos textos.

Iniciamos nossa análise procurando compreender qual o sentido que os professores atribuíram à realização dos relatos de experiência. Dois sentidos emergiram: o primeiro, de divulgaçáo das atividades desenvolvidas nas SRM, é compreensível se considerarmos que, desde a matrícula específica dos estudantes para participação nas atividades do AEE, é solicitado aos pais que deixem previamente autorizada a utilização das imagens dos alunos em atividade, um indicativo da intenção de dar publicidade aos trabalhos desenvolvidos.

Outro sentido atribuído foi o de possibilidade de reconstrução da prática por meio da reflexão sobre ela. Há discursos que pontuam esse momento como "rico e revelador para nosso fazer profissional" ou afirmaçóes de que "esse trabalho foi transformador para observarmos o que tínhamos e o que temos na nossa escola, o ideal e o que é real, o que fizemos e o que podemos fazer". Valoriza-se também a articulação e escuta partilhada entre pais e profissionais da escola como mobilizador de açóes com o objetivo de incluir a todos os estudantes.

Essa diversidade de sentidos reflete-se, também, na consistência das experiências desenvolvidas. É notório que, nos relatos cujo entendimento se fixa mais nos aspectos de divulgação, as atividades realizadas trazem as marcas da realização de fotos, fôlderes, cartazes, painéis, enfim, materiais destinados ao público externo. Isso se diferencia significativamente dos relatos que, entendendo ser esse um momento formativo, direcionam suas atividades para o desenvolvimento de inovaçôes pedagó- 
gicas junto ao público interno das salas de recursos multifuncionais ou para a formação dos professores das classes regulares.

Os textos apresentam uma revisão teórica das questóes relativas à educação especial e à inclusão retomando questões relativas à história da educação especial e à legislação e normas específicas.

$\mathrm{Na}$ sequência, a estruturação textual contempla os aspectos metodológicos. Em sua maior parte, os relatos são enquadrados como pesquisas qualitativas. Em casos isolados, vemos enquadramentos teórico-metodológicos adequadamente desenvolvidos nas perspectivas de pesquisa-ação e pesquisa-ação colaborativa, articulada ainda às concepçóes do ensino colaborativo.

Das atividades priorizadas nas açóes desenvolvidas, nove destinam-se aos estudantes, oito direcionam-se para a melhoria do envolvimento da comunidade escolar, quatro dedicam-se a promover a integração das famílias no trabalho. Quatro relacionam-se à formação de professores, três divulgam temas nas datas comemorativas e dois descrevem o cotidiano do atendimento da SRM, sem apresentar um projeto específico.

A demarcação das questóes da deficiência a partir do calendário de datas alusivas às deficiências e outras situaçóes análogas enfatiza a realização de divulgação nas seguintes datas: Dia Nacional de Luta da Pessoa com Deficiência, Dia Nacional de Conscientização do Autismo, Dia Nacional do Braille, Semana Nacional das Pessoas com Deficiência Intelectual e Múltipla, Dia Nacional do Surdo, Dia Internacional da Pessoa com Deficiência Física, entre outros.

Outro sentido que buscamos analisar é de qual a compreensão manifesta pelos professores quanto aos sentidos da inclusão e da implantaçáo das salas de recursos multifuncionais. Vemos uma ampla gama de possibilidades, partindo de textos que entendem ser a inclusão uma imposição legal, mesmo quando resultante da conquista de lutas de populaçóes historicamente discriminadas, e outros que compreendem esse processo como imperativo ético da atualidade.

E como os professores entendem que deve dar-se a efetivação dos processos inclusivos? O trabalho em equipe é dos temas mais destacados como relevante à efetiva inclusão. De maneira geral, os relatos apontam a relevância de que o trabalho desenvolvido pelos professores do 
atendimento educacional especializado se coloque para além do espaço das SRM. Há a sinalização da busca de articulaçóes com os professores do ensino regular, profissionais de apoio e também a demarcação quanto à importância da interlocução com as equipes de apoio da Secretaria Municipal de Educação e Cultura (SMEC) que, nas visitas às escolas, trazem contribuiçóes e orientaçóes ao trabalho.

É curiosa a relação descrita com os cuidadores que, como se apresenta nos relatos, é restrita a demarcação de suas funçóes e obrigaçóes a partir da orientação normativa constante em lei. Em apenas um dos 30 relatos analisados encontramos a atribuição de um sentido de importância ao trabalho desenvolvido por esse profissional para viabilizar os processos de escolarizaçáo dos estudantes.

Por fim, considerando-se a existência, desde o início da década de 1990, do CMIEE, é relevante analisar de que forma a equipe se insere, atualmente, como produtora de discursos a área da educação especial em Boa Vista. No relato de experiência apresentado, indica-se que o CMIEE atendia, em 2016, a 201 estudantes das redes pública e privada, mas que tinha uma lista de espera (não quantificada) em decorrência dos limites do espaço físico e de pessoal.

Dois elementos que nos parecem passíveis de análises mais relevantes e que demandariam aprofundamentos quanto aos sentidos que atravessam os discursos apresentados são: em um momento de quantificação dos atendimentos realizados, o gráfico apresentado distingue AEE dos atendimentos em psicologia, fonoaudiologia, fisioterapia e terapia ocupacional, ficando subentendido serem atendimentos distintos do que seria a atividade educativa em si, o que nos parece relevante em termos de entendimento do sentido da educação especial cujas origens, ao remontarem a uma tradição médico-biológica, por vezes, foram confundidas com essas práticas que não se constituem, necessariamente, em elementos da educação escolar.

Outro aspecto de destaque é que, em suas consideraçóes finais, a equipe do CMIEE destaca seu papel no fortalecimento de processos de inclusão social, perspectiva que se expande em relação à educação escolar e reafirma, como proposta, de favorecer a inclusão da pessoa com deficiência nos diversos segmentos da sociedade. Entendemos, como destaca Bakhtin (1992, p. 319): 
O objeto do discurso de um locutor, seja ele qual for, não é objeto do discurso pela primeira vez enunciado, e este locutor náo é o primeiro a falar dele. $\mathrm{O}$ objeto, por assim dizer, já foi falado, controvertido, esclarecido e julgado de diversas maneiras, é o lugar onde se cruza, se encontram e se separam diferentes pontos de vista, visões de mundo, tendências.

Nesse sentido, vemos que um discurso demarcando o papel de inclusão social em seu sentido mais amplo a um centro que se origina no sistema educacional, traz indícios importantes de um percurso do que se pode inferir ser de reorientação ou de abertura na amplitude para o alcance das açóes, diante do fato de que a política de educação especial oficialmente direciona-se em sua quase totalidade à instalação e fortalecimento de SRM.

\section{CONSIDERAÇÕES FINAIS}

A incorporação de políticas emanadas de órgãos do governo federal que orientam a educação, em um país de dimensôes continentais e com realidades e processos históricos tấo diversificados como o Brasil passa, evidentemente, por leituras e entendimentos diferenciados.

Em Boa Vista, a proposiçáo de ter salas de recursos multifuncionais distribuídas por todas as escolas da rede pública de ensino, principal ação proposta e subsidiada pelo governo federal, se materializa na implantação de espaços e investimento na formação continuada dos docentes. Observamos que esses espaços estabelecidos nas escolas passam a ter maior priorizaçáo de recursos, equipamentos e investimento na contrataçáo e formaçáo de pessoal, relegando o Centro Municipal Integrado de Educação Especial a um espaço de menor representatividade, mantendo-se nele uma infraestrutura que atende a uma parcela numericamente inexpressiva diante do crescimento da presença de estudantes público-alvo da educaçáo especial em todo o sistema.

Seguindo o já destacado por Baptista (2011), Milanesi (2012) e Pasian, Mendes e Cia (2014), a adoção de SRM como política que foi enfatizada ou adotada como alternativa única se materializa, com rigor, na criação de categoria profissional correspondente no plano de cargos, 
carreira e remuneração em uma explicita confusão entre o sentido da educação especial como campo científico e profissional e o exercício da atividade do professor em uma das possíveis modalidades de atendimento educacional especializado.

Do processo de interlocução proposto aos professores nas Mostras de Educação Especial, destacamos a relevância de que, nos relatos de experiência apresentados sejam referenciados o estudo e reflexão de obras recentes de destaque na área em uma regiáo em que as dificuldades de formação e atualização são profundas.

Observa-se a emergente ideia, explicitada em alguns textos, da realização de Planos Individuais do Estudante ou de Planos Específicos Individuais como nominados em diferentes relatos, mas trazendo como elemento comum a estrutura de focarem em domínios cognitivo, motor, pessoal e social. Essa perspectiva de individualização do ensino, pouco comum nos processos históricos de escolarização no Brasil, é prática que, em nosso entendimento, demandará um maior acompanhamento de sua projeção e execução no cotidiano.

Além disso, vemos um percurso promissor em construção quando consideramos experiências de trabalho ricas e criativas, como as atividades artísticas trazidas ao ensino nas SRM, as práticas de ensino colaborativo e a produção de espaços onde a formação dos professores parte da realidade em que se encontra, com seus problemas e sentidos reais trazidos ao debate, socialização e valorização.

A ênfase posta no modelo de salas de recursos multifuncionais, como evidenciado nesse estudo, nos alerta para a relevância de estarmos atentos às açóes desenvolvidas nesses espaços, investindo em estudos e pesquisas que possam identificar até que ponto há resultados desse modelo de atendimento em garantir aos estudantes público-alvo da educação especial o acesso ao currículo escolar, direito inalienável de todos os estudantes.

\section{REFERÊNCIAS}

BAKHTIN, M. Marxismo e filosofia da linguagem. São Paulo: Hucitec, 2006. . Os gêneros do discurso. In: BAKHTIN, M. Estética da criação verbal. São Paulo: Martins Fontes, 1992. 
BAPTISTA, C.R. Ação pedagógica e educação especial: a sala de recursos como prioridade na oferta de serviços especializados. Revista Brasileira de Educação Especial, Marília, v. 17, p. 59-76, 2011. http://dx.doi.org/10.1590/S1413$\underline{65382011000400006}$

BOA VISTA. Coordenação de Educação Especial. Resultados de um processo. Boa Vista: Coordenação de Educação Especial, 2012a. (mimeo.)

. Prefeitura. Lei $n^{\circ} 1.411$, de 25 de abril de 2012: altera a Lei no 712, de 9 de dezembro de 2003, para criar a especialidade de cuidador na estrutura de cargos, carreiras e remuneração dos servidores. Boa Vista, 2012b.

BRASIL. Ministério da Educação. Secretaria de Educação Especial. Sala de recursos multifuncionais: espaços para atendimento educacional especializado. Brasília: Ministério da Educação, Secretaria de Educação Especial, 2006.

MENDES, E.G. A formação do professor e a política nacional de Educação Especial. In: SEMINÁRIO NACIONAL DE PESQUISA EM EDUCAÇÃO ESPECIAL: FORMAÇÃO DE PROFESSORES EM FOCO, 2009, São Paulo. Anais... São Paulo, 2009. 1 CD-ROM.

- Deficiência mental: a construçáo científica de um conceito e a realidade educacional. São Paulo: USP, 1995.

MILANESI, J.B. Organização e funcionamento das salas de recursos multifuncionais em um município paulista. 183f. Dissertação (Mestrado) - Universidade Federal de São Carlos, 2012.

PASIAN, M.S.; MENDES, E.G.; CIA, F. Salas de recursos multifuncionais: revisão de artigos científicos. Revista Eletrônica de Educação, v. 8, n. 3, p. 213225, 2014. http://dx.doi.org/10.14244/19827199949

SIEMS, M.E.R. Educação Especial em Roraima - 1970-2001: efeitos do regime militar. São Carlos: Pedro e João Editores, 2016.

Recebido em 15 de maio de 2018.

Aprovado em 02 de agosto de 2018. 